\title{
Urban electric vehicles: a contemporary business case
}

\author{
Noha Sadek
}

Received: 12 October 2010 / Accepted: 3 November 2011 / Published online: 3 January 2012

(C) The Author(s) 2011. This article is published with open access at SpringerLink.com

\begin{abstract}
Background High gasoline prices, global warming, pollution and dependence on foreign sources of oil are four major issues the world is facing today. In a world where energy supply security and environmental protection are major concerns, the development of green vehicles is becoming a necessity. The Electric vehicle (EV) is one of the most promising technologies that will make the "green dream" come true.

Methods A contemporary business case that encourages the immediate deployment of urban EVs is presented. It proposes a model in which we can profit from the benefits of urban EVs namely, high energy efficiency, emissions reduction, small size and noise reduction. The model mitigates the EV potential limitations such as energy source, charging infrastructure, impact on electrical power system and cost issues. It also provides ideas to overcome the barriers of the technology application in order to speed up their commercialization.

Concluding remarks Energy conservation and environmental protection are the main driving forces behind the development of electric vehicles. Urban EVs seem to be a good choice for cities and urban centers since their potential drawbacks are few and can be mitigated. This study reveals that having an environmentally friendly vehicle can soon become a reality if collaborative efforts are properly directed.
\end{abstract}

Keywords Electric vehicle $\cdot$ Zero emissions vehicle Energy efficiency $\cdot$ Business case $\cdot$ Alternative vehicle

\footnotetext{
N. Sadek $(\bowtie)$

The American University in Cairo, Cairo, Egypt

e-mail: nohams@yahoo.com
}

\author{
Abbreviations \\ EV Electric vehicle \\ ICEV Internal combustion engine vehicle \\ MpG Miles per gallon \\ BOM Battery ownership model \\ BLM Battery leasing model
}

\section{Introduction}

High gasoline prices, global warming, pollution and dependence on foreign sources of oil are four major issues the world is facing today. The portion of oil used for transportation is growing and is projected to use $68 \%$ of liquid fuel energy over the period 2004-2030 [1]. Moreover, transport emissions are estimated to increase by $84 \%$ in 2030 [2]. Today, approximately 900 million vehicles worldwide are on the roads and there are estimates for the year 2020 that this number will increase to 1.1 billion [3], which will inevitably have consequences on oil demand and $\mathrm{CO}_{2}$ emissions. Since this will have a negative impact economically, ecologically and politically, a strategy to replace fossil fuels as a source of energy for vehicles is urgently required. The Electric vehicle $(\mathrm{EV})$ is the natural vehicle evolution in this direction. On the other hand, having alternative energy sources will reduce the nearly total dependency on oil.

This paper presents a contemporary business case for the electric vehicle; it proposes a business model for urban EVs intended for near-term deployment. Subsequently, their main advantages, namely, high efficiency, reduction of emissions, energy security, and noise reduction are discussed in detail. For a complete analysis, EV limitations and potential challenges like energy source concerns, charging infrastructure issues, impact on electrical power 
system and cost issues are analyzed. To support the case of urban EVs, a mitigation technique is proposed for each limitation and the commercialization aspects are evaluated. Finally, the current case of EVs is summarized and a recommendation is provided for the next step that should be followed to achieve the intended evolution in the current transportation system.

\section{Proposed model}

A lot of literature is concerned with how EVs can compete with other vehicles (gasoline and other alternative vehicles) $[2,4,5]$. The author, however, believes that a competition with Internal Combustion Engine Vehicles (ICEVs) should not be the target at the current stage. On one side, the effort, time and money spent for the development of ICEVs until today should be considered. The ICEVs of today are the result of decades of high budget research and development. On the other side, competition of EVs with conventional vehicles in all applications will not be possible, at least in the current stage. This is due to some unresolved EV technical and marketing issues. So, ICEVs and EVs will continue to co-exist side by side in the market. Consequently, at this stage we must define the niche markets that are feasible for EVs. Accordingly, the EV is believed to be mainly suitable for short-range low-speed transportation which includes urban vehicles, electric bikes and golf cars.

The proposed model is thus based on the main concept of using the right tool for the right distance rather than using ICEVs for all applications. The model will focus on urban electric vehicles used in large cities and urban centers where low-speed traffic is a typical characteristic. The scenario matches with the motorists' driving habits especially the average distance traveled every day. Data collected by the National Personal Transportation Survey (NPTS) in 1995 indicates that the majority of US daily mileages are relatively short, with $50 \%$ of days being less than 30 miles per day (48 $\mathrm{km}$ per day) [6]. On the other hand, statistics in Germany indicate that $90 \%$ of daily driving is in the range of 62 miles per day ( $100 \mathrm{~km}$ per day) [3]. Accordingly, the proposed model of an urban EV with 60 miles $(97 \mathrm{~km})$ range, $90 \mathrm{~km} / \mathrm{h}$ top speed and Lithium-ion battery will be the focus of this study. The following analysis investigates the various benefits and costs of the proposed urban EV and shows that it is a compelling business case that deserves to be examined and nurtured.

\section{Why electric vehicles?}

The advantages of EVs, with a focus on our proposed urban $\mathrm{EV}$, will be presented as follows:

\subsection{Gasoline savings and energy security}

The deployment of electric vehicles will lead to significant fuel savings and will diminish the problems associated with oil dependency. A complete dependence on oil, especially foreign oil, is a risk in case of a gasoline shutdown or political problems leading to oil supply interruption or in case of an extreme gasoline price spike. Since $95 \%$ of the energy used to recharge EVs comes from domestic sources [7], EVs reduce substantially dependence on foreign oil limiting the possible economic damages resulting from the above events. A big benefit obtained from using electric vehicles is, thus, the security in case of a gasoline shortage.

On the other hand, the continuous increase in gasoline consumption combined with high gasoline prices represents a threat to the world economy. Currently, the United States uses more than 20 million barrels of oil per day, two thirds of which is used for transportation. Oil imports cost about $\$ 5.7$ billion a week [8]. Depending on its price, oil has accounted for between $30 \%$ and $59 \%$ of the U.S. trade deficit over the last decade [9]. Additionally, forecasts by the Energy Information Agency (EIA) anticipate a rise in oil prices over the next two decades where the U.S. gasoline price is predicted to rise to $\$ 4$ per gallon by 2030 in the baseline scenario and to over $\$ 5.5$ per gallon in the high price scenario [9]. The main reasons behind future inflation in oil prices are the rising oil extraction costs, as well as, the increasing energy demand from developing countries, especially China and India. China has been experiencing very rapid growth in vehicle population where it was about 63 million in 2008 , and it is projected to be $550-730$ million by 2050, 38-83\% higher than that of the U.S. in 2050 [10].

To get a clear idea about the gasoline savings of electric vehicles, we will start by calculating the gasoline consumption in conventional vehicles based on EPA (Environmental Protection Agency) data [11]. The average fuel consumption of conventional vehicles ranges from $18 \mathrm{MpG}(7.7 \mathrm{~km} / \mathrm{L})$ to $25 \mathrm{MpG}(10.6 \mathrm{~km} / \mathrm{L})$. For easy comparison with the urban vehicle model proposed above, we can safely assume that vehicles drive on average 20,000 miles $(32187 \mathrm{~km})$ per year (given the 60 mile/97 km daily mileage). The gasoline consumption thus, ranges from 800 to 1100 gal (3028 to $4164 \mathrm{~L}$ ) per year. For an average gasoline price of $\$ 3 / \mathrm{gal}$, fuel savings range from $\$ 2400$ to $\$ 3300$ per year. Of course, these gasoline savings imply an increase in electricity consumption for charging the batteries of electric vehicles. Field tests indicate that the energy consumption of modern urban EVs varies from 0.2 to $0.3 \mathrm{kWh} /$ mile (0.12 to $0.19 \mathrm{kWh} / \mathrm{km})[2,12,13]$ so, the total electricity consumption is calculated to be from 4000 to $6000 \mathrm{kWh}$ per year. Therefore, for the current average electricity US price of 10 cents per kWh [14], EV electricity consumption per year ranges from $\$ 400$ to $\$ 600$. It is obvious that the annual fuel 
cost of an urban electric vehicle is about 6 times less than a gasoline one.

\subsection{High energy efficiency}

Another advantage of EVs is their high energy efficiency when compared with conventional vehicles.

For a fair comparison of EV efficiency with that of ICEV, well-to-wheel rather than tank-to-wheel efficiency factors are considered. The well-to-wheel analysis considers the whole energy life-cycle; starting from the extraction of energy from natural resources through transportation and distribution, and ending with transformation into kinetic energy to the wheels. Calculations of energy efficiency and consumption are given by the following equations [12].

$E_{W 2 W}=E_{W 2 T} \times E_{T 2 W}$

where $E_{W 2 W}$ is the Well-to-Wheel energy efficiency, $E_{W 2 T}$ is the Well-to-Tank energy efficiency and $E_{T 2 W}$ is the Tank-toWheel energy efficiency

$C_{T 2 W}=C_{W 2 W} \times E_{W 2 T}$

where $C_{T 2 W}$ is the Tank-to-Wheel energy consumption, $C_{W 2 W}$ is the Well-to-Wheel energy consumption and $E_{W 2 T}$ is the Well-to-Tank energy efficiency.

\subsubsection{EV energy efficiency}

The Well-to-Tank efficiency takes into account the energy lost during production and distribution of the electricity. Energy efficiency of electricity production varies widely depending on the type of power plant (coal-based, naturalgas based; conventional or combined cycle power plants). An average figure of $40 \%$ has been reported [12]. The average energy efficiency of electricity distribution is around $92.5 \%$ [12]. The Well-to-Tank energy efficiency can be thus calculated to be around $37 \%(40 \% * 92.5 \%)$.

The Tank-to-Wheel energy efficiency depends on battery charging/discharging, charger, electric motor efficiency and electronic engine management whose average Tank-to-Wheel efficiency values are as follows: $90 \%, 89 \%, 92.5 \%$ and $97 \%$ respectively in our proposed urban lithium-ion EV. The Tank-to-Wheel energy efficiency for Lithium-ion battery is thus around $72 \%(90 \% * 89 \% * 92.5 \% * 97 \%)$ [12].

Using Eq. 1, the Well-to-Wheel energy efficiency of EVs is around $27 \%$.

\subsubsection{ICEV energy efficiency}

While the Well-to-Tank energy efficiency is around $83 \%$ taking into account the production, refining and transpor- tation of fuel, the Tank-to-Wheel energy efficiency of ICEVs is quite low: around $18 \%$ [12]. In addition to the heat energy lost during the combustion process, additional energy is lost due to the friction of moving parts between the engine and the wheels.

Using Eq. 1, the Well-to-Wheel energy efficiency of ICEVs is calculated to be approximately $15 \%(83 \% * 18 \%)$.

Table 1 illustrates that EVs are almost twice as efficient as ICEVs, from a Well-to-Wheel perspective.

The above data will be used to calculate the energy consumption of our proposed urban EV relative to a sample ICEV. Considering the current EV market figures, it is reasonable to assume that our proposed urban EV has a Tank-to-Wheel energy consumption of $0.2 \mathrm{kWh}$ per mile $(0.12 \mathrm{kWh} / \mathrm{km})[12,13]$. Using Eq. 2, the Well-to-Wheel consumption of the 60 -mile $(97 \mathrm{~km})$ urban EV is $0.5 \mathrm{kWh}$ per mile $(0.31 \mathrm{kWh} / \mathrm{km})$.

To compare with ICEVs, the 2008 Toyota Prius will be taken as a reference since it is one of the most efficient ICEVs on the market. Considering our urban driving model, the fuel consumption city estimate of the Prius is $48 \mathrm{MpG}(20.4 \mathrm{~km} / \mathrm{L})$ [11]. With a gasoline energy density of $33.7 \mathrm{kWh}$ per gallon [15], the Tank-to-Wheel energy is $0.7 \mathrm{kWh}$ per mile $(0.44 \mathrm{kWh} / \mathrm{km})$. Again using Eq. 2, the Well-to-Wheel consumption of the Prius is $0.8 \mathrm{kWh}$ per mile $(0.5 \mathrm{kWh} / \mathrm{km})$.

It can thus be concluded that our proposed urban EV model can offer higher energy efficiency than that offered by a conventional ICEV. Moreover, it is important to note that the EV Well-to-Tank energy efficiency can be further improved if electricity production process is optimized, as will be discussed later.

\subsection{Emissions reduction}

Climate change is currently the most significant long-term threat to the global environment and man-made emissions of greenhouse gases are the main cause of the observed global warming over the last 50 years. Fossil fuels, such as gasoline, are considered the major contributor to global climate change since burning them releases greenhouse gases $\left(\mathrm{CO}_{2}, \mathrm{NO}_{\mathrm{x}}, \mathrm{SO}_{2}\right)$ into the atmosphere. Additional runoff pollutants, such as heavy metals, oils and grease, are also produced. In addition to global warming, these pollutants are known to cause respiratory and heart
Table 1 Comparison of EVs and ICEVs energy efficiencies

\begin{tabular}{lcc}
\hline & ICEV & EV \\
\hline Well-to-Tank & $83 \%$ & $37 \%$ \\
Tank-to-Wheel & $18 \%$ & $72 \%$ \\
Well-to-Wheel & $15 \%$ & $27 \%$ \\
\hline
\end{tabular}


diseases, and are well-known carcinogens. They are also the leading causes of smog and acid rain. Carbon Dioxide $\left(\mathrm{CO}_{2}\right)$ is the most important human made greenhouse gas, and only the highway vehicles account for $26 \%$ of U.S. $\mathrm{CO}_{2}$ emissions each year [11].

Since EVs use electricity as a fuel, substantial reductions in greenhouse gas emissions are expected. In fact, the magnitude of reduction depends on the source used to generate the electricity. Electricity generated from noncarbon sources (renewables, nuclear, or hydroelectric) produce much less gas emissions than that generated from carbon sources. According to the Center for Entrepreneurship and Technology (CET) of University of California, if the electricity to power electric cars is produced by non-carbon sources the range of expected greenhouse gas reductions in 2030 is between $25 \%$ and $62 \%$ [9]. On the other hand, EVs do not promise much benefit in reducing emissions in countries such as China where electricity is primarily generated from coal. Contrarily, they could increase emissions of criteria pollutants like $\mathrm{SO}_{2}$ and $\mathrm{NO}_{\mathrm{x}}$ because power plants are believed to be the largest contributor to China's $\mathrm{SO}_{2}$ and $\mathrm{NO}_{\mathrm{x}}$ emissions [10].

It is important to examine the $\mathrm{CO}_{2}$ emissions of urban EVs versus those of ICEVs. $20 \mathrm{lb}$ of $\mathrm{CO}_{2}$ are generated for every gallon $(2.4 \mathrm{~kg} / \mathrm{L})$ of gasoline burnt in ICEVs [11]. Using the fuel consumption range (800-1100 gal per year) that was previously calculated, a typical ICEV releases around 16000 to $22000 \mathrm{lb}$ (7 to $10 \mathrm{t}$ ) of $\mathrm{CO}_{2}$ each year.

On the other hand, EVs emit nothing during their operation; so, their tank-to-wheel $\mathrm{CO}_{2}$ emissions are zero. It is however more practical to know the Well-to-Wheel $\mathrm{CO}_{2}$ emissions generated not only by the vehicle, but also by the power plant and by the distribution of the electricity. EVs generate around $616 \mathrm{~g}$ of $\mathrm{CO}_{2}$ for each $\mathrm{kWh}$ of transmitted energy with lithium batteries [12]. For an urban EV yearly consumption of 4000 to $6000 \mathrm{kWh}, 2.5$ to $3.7 \mathrm{t}$ of $\mathrm{CO}_{2}$ are emitted per year. That means that with the average European Union electricity mix, Well-to-Wheel $\mathrm{CO}_{2}$ emissions of an electric vehicle are about 2.5 times less than those of a gasoline vehicle. If electricity is generated from solar energy, an average of $130 \mathrm{~g}$ is emitted for every $\mathrm{kWh}$ of generated electricity so, the annual $\mathrm{CO}_{2}$ emissions range from 0.5 to $0.8 \mathrm{t}$. The annual emissions may be further reduced to 0.07 to $0.1 \mathrm{t}$, if wind energy is used. This is the case in countries such as Norway, Sweden, Switzerland and France which would have maximal leverage for climate improvement [12]. Furthermore, the EV Well-to-Wheel emissions can even reach zero if nuclear energy is used in electricity generation.

As for the environmental impact of the battery in EVs, a life-cycle assessment is necessary to evaluate the energy and material flows in all stages of the battery's lifetime and the associated wastes and emissions released to the environment. A study reveals that the impact of a Li-ion battery used in EVs is relatively small. In contrast, it is the operation phase that remains the dominant contributor to the environmental burden as long as the electricity for the $\mathrm{EV}$ is not produced by renewable resources. Thus, a Lithium-ion battery in an urban EV does not lead to an overcompensation of the potential benefits of the higher efficiency of EV compared to an ICEV [16].

In view of the above, using urban EVs can substantially reduce $\mathrm{CO}_{2}$ emissions. They become even more attractive in countries where renewable sources are used in electricity generation.

\subsection{Small size and light weight}

Many people think that EVs are bigger and heavier than conventional ones because of their use of large batteries. This might be true for long range vehicles that require big heavy batteries. However, with our proposed model (shortrange urban vehicles), EVs are smaller and lighter than conventional ones.

The battery is usually considered the main component in the EV weight. So, it is important to examine the battery weight in the urban EV model. As will be explained later, the proposed urban EV will use a Lithium-ion battery with average specific energy $0.13 \mathrm{kWh} / \mathrm{Kg}$. For a 60 -mile $0.2 \mathrm{kWh} / \mathrm{mile}(97-\mathrm{mile}-0.12 \mathrm{kWh} / \mathrm{km}$ ) urban vehicle, the total needed battery capacity would be $12 \mathrm{kWh}$. Therefore, the expected battery weight is about $90 \mathrm{~kg}$ which is quite satisfactory for an urban EV. Market data in Table 2 shows that commercial urban EVs are lighter and smaller than comparable ICEVs (like the Honda Civic coupe). For longrange EVs however, the weight/size is equal to, or even higher, than ICEVs. This is due to the heavy and large batteries used for long EV ranges.

It can be noted that the EV is lighter than the ICEV due to several reasons. The heavy acoustic insulation necessary in ICEVs to damp the sound of the engine, is not required in EVs. Moreover, the electric motor of an EV is much lighter than the internal combustion engine of a conventional vehicle delivering the same power. In addition to the fact that the EV does not need manual or automatic gearbox, it is also possible to eliminate every mechanical transmission using wheel-drive motors. Furthermore, future advancements in battery technology will make batteries smaller and lighter which will in turn lead to further reductions in weight and size of the EV.

The data in Table 2 also shows that the EV dimensions are generally less than the ICEV ones. The small size of EVs is useful in short trips which are often made in intense traffic conditions and with a single person or a couple of 
Table 2 Comparison of typical electric and gasoline vehicles

\begin{tabular}{|c|c|c|c|c|c|c|c|}
\hline Vehicle & $\begin{array}{l}\text { Curb } \\
\text { weight (kg) }\end{array}$ & $\begin{array}{l}\text { Battery } \\
\text { weight (kg) }\end{array}$ & $\begin{array}{l}\text { Range } \\
(\mathrm{km})\end{array}$ & Battery type & $\begin{array}{l}\text { Car price } \\
\text { (US\$) }\end{array}$ & Dimensions (m) & Data source \\
\hline \multicolumn{8}{|c|}{ Internal Combustion Engine Vehicles } \\
\hline Honda Civic Si coupe & 1310 & N/A & N/A & N/A & 21,000 & $4.5 * 1.8 * 1.4$ & www.honda.com \\
\hline Smart for Two 2007 & 730 & N/A & N/A & N/A & 21,700 & $2.5 * 1.5 * 1.6$ & www.smartusa.com \\
\hline Mazda MX-5 2010 & 1100 & N/A & $\mathrm{N} / \mathrm{A}$ & N/A & 25,000 & $4 * 1.7 * 1.3$ & www.mazda.com \\
\hline Toyota Prius 2009 & 1380 & N/A & N/A & N/A & 25,000 & $4.5 * 1.8 * 1.5$ & www.toyota.com \\
\hline Honda Accord EX & 1535 & N/A & N/A & N/A & 24,000 & $4.9 * 1.9 * 1.5$ & www.honda.com \\
\hline Mitsubishi Galant SE & 1545 & N/A & N/A & N/A & 24,800 & $4.9 * 1.9 * 1.5$ & www.mitsubishi-motors.com \\
\hline \multicolumn{8}{|l|}{ Electric Vehicles } \\
\hline Zenn 2009 & 620 & 180 & 80 & Lead acid & 10,000 & $3.1 * 1.6 * 1.4$ & www.zenncars.com \\
\hline Xebra Electric Sedan & 655 & 136 & 40 & Lead acid & 11,900 & $2.9 * 1.4 * 1.6$ & www.zapworld.com \\
\hline REVAi & 665 & 270 & 80 & Lead acid & 12,000 & $2.5 * 1.3 * 1.5$ & www.revaindia.com \\
\hline Reva G-Wiz & 475 & 75 & 112 & Li-ion & 16,731 & $2.6 * 1.3 * 1.6$ & www.revaindia.com \\
\hline Miles ZX40S & 1066 & 300 & 80 & Lead acid & 20,800 & $3.4 * 1.5 * 1.7$ & www.milesev.com \\
\hline Wheego 2011 & 1200 & 230 & 160 & Li-ion & 26,500 & $3 * 1.6 * 1.6$ & www.wheego.net \\
\hline Mitsubishi iMieV 2009 & 1080 & 130 & 160 & Li-ion & 30,500 & $3.4 * 1.5 * 1.6$ & www.mitsubishi-motors.com \\
\hline Nissan Leaf & 1600 & 300 & 160 & Li-ion & 32,800 & $4.4 * 1.8 * 1.6$ & www.nissanusa.com/leaf-electric-car \\
\hline Nissan Altra & 1700 & 350 & 190 & Li-ion & 50,000 & $184 * 1.8 * 1.7$ & $\begin{array}{l}\text { http://avt.inel.gov/pdf/fsev/sce_rpt/ } \\
\text { altra_report.pdf }\end{array}$ \\
\hline Tesla Roadster & 1220 & 410 & 400 & Li-ion & 101,500 & $3.9 * 1.9 * 1.1$ & www.teslamotors.com \\
\hline
\end{tabular}

N/A: Not Applicable

persons on board. A small car is better because it can be easily maneuvered in high traffic and can be parked easily and consequently, reducing the parking congestion problem.

\subsection{Unique features}

The EV has some unique features which distinguish it from other conventional or alternative vehicles. An electric motor is much simpler than internal combustion engines [4] and because of this simplicity, EVs may be more reliable and can resist very hard work. On the other hand, torque generation of an electric motor is very quick and accurate. Also, a motor which can be attached to each wheel further improves the driving capabilities of EV. Moreover, motor torque can be measured easily; an advantage that allows application of new control strategies based on road condition estimation [17]. Furthermore, energy can be generated onboard through the regenerative braking technique.

Besides, the use of urban EVs can reduce the high levels of city noise. Road traffic, mainly caused by ICEVs, is known to be the cause of the majority of noise in cities. In conventional vehicles, noise is mainly generated from the internal combustion engine. Since an electric motor rather than an internal combustion engine is used, EVs are very silent. So, their widespread use in cities can significantly reduce urban noise levels.

\section{Present major issues}

It is widely believed that EVs are impractical due to their range limitations, high cost, energy storage constraints and missing charging infrastructure. Thus, some people prefer to postpone their use until further advancements in the supporting technologies. This paper, however, proposes the immediate use of urban EVs based on the belief that their limitations are few and can be mitigated using various techniques. Advancements in technology would be a motive to a wider use of EVs rather than a trigger to start their commercialization. The following discussion is concerned with the current EV limitations along with proposed methods to overcome those limitations. Evidence is provided based on the proposed urban EV model.

\subsection{Energy source}

The EV energy source has been identified to be the major obstacle of its commercialization [4, 18-21].

The main energy storage requirements for EV applications are summarized as follows:

- Specific energy $(\mathrm{kWh} / \mathrm{kg})$ and energy density $(\mathrm{kWh} / \mathrm{L})$ high enough to ensure a desired driving range.

- Specific power $(\mathrm{kW} / \mathrm{kg})$ and power density $(\mathrm{kW} / \mathrm{L})$ sufficiently high to give good acceleration, allow fast 
charging and good regenerative braking to achieve high-energy efficiency.

- Fast charging and deep discharging capabilities.

- Long cycle and service lives to meet the general standard of automotive component life.

- Durability against environmental demands (e.g. mechanical or climatic stress) so that EVs can work in harsh environments, if needed.

- Safety under extreme conditions (short-circuits, overcharge,...etc.)

- Cost effectiveness for EVs to be able to compete with other conventional or alternative vehicles.

- Environmentally friendly and recyclable

- Easy maintenance

The USABC (United States Advanced Battery Consortium) aims to make EVs compete with ICEVs. So, it has set performance goals of EV batteries. As shown in Table 3, these goals are so demanding that no existing battery is capable of meeting all its criteria.

As mentioned before, today we do not seek competition with long range vehicles (ICEVs or other alternative vehicles). Instead, we aim at a battery technology to satisfy our current needs. The proposed urban EV for short-range low-speed applications requires only a small battery thus; a battery capacity of $20 \mathrm{kWh}(90 \mathrm{~kg})$ is enough for such vehicles. As demonstrated in Table 3, Li-ion, Ni-Cd and Ni$\mathrm{MH}$ batteries seem to be viable options for the near-term needs. While Ni-Cd and Ni-MH have demonstrated to be good options for EVs, Lithium-ion batteries have just started to unfold their potential. It is their significantly higher specific energy that makes a high-volume market entry of EVs possible [4]. Their very high specific power $(350 \mathrm{~W} / \mathrm{kg})$ is a useful feature for urban EVs; where a good acceleration and regenerative braking are required in high traffic areas. Additionally, their very high specific energy

Table 3 Comparison of different energy storage systems [4]

\begin{tabular}{lllll}
\hline Energy source & $\begin{array}{l}\text { Specific } \\
\text { energy } \\
(\mathrm{Wh} / \mathrm{kg})\end{array}$ & $\begin{array}{l}\text { Specific } \\
\text { power } \\
(\mathrm{W} / \mathrm{kg})\end{array}$ & $\begin{array}{l}\text { Cycle life } \\
\text { (cycles) }\end{array}$ & $\begin{array}{l}\text { Cost } \\
(\$ / \mathrm{kWh})\end{array}$ \\
\hline USABC $^{\mathrm{a}}$ & 200 & 400 & 1000 & 100 \\
Lead-acid & 35 & 150 & 700 & 150 \\
Ni-Cd & 60 & 300 & 1200 & 1000 \\
Ni-MH & 70 & 220 & 1500 & 1200 \\
Li-ion & 130 & 350 & 1000 & 500 \\
Na-NiCl & 110 & 150 & 1500 & 700 \\
Zn-O2 & 200 & 100 & $1($ electric fuel $)$ & 5000 \\
Flywheels & 40 & 3000 & 5000 & 20000 \\
Ultracapacitors & 5 & 2000 & 500000 & 12000 \\
\hline
\end{tabular}

${ }^{\mathrm{a} U S A B C}$ :United States Advanced Battery Consortium
$(130 \mathrm{Wh} / \mathrm{kg}$ ) allows the use of a relatively small $90 \mathrm{~kg}$ battery for the 60-mile desired range. The average Li-ion battery cost is $\$ 500$ per $\mathrm{kWh}[22,23]$. Although the current cost of the $12 \mathrm{kWh}$ battery is relatively high $\$ 6,000$ $(12 \mathrm{kWh} * \$ 500 / \mathrm{kWh})$, it is expected to decrease in the future due to technological advancements [18]. Consequently, the Lithium-ion is a good candidate for our proposed model of urban EVs.

Considering the above scenario, most of the battery issues (heavy weight, range, performance, and charging time) no longer exist. On the other hand, the future of energy storage technologies is very promising; Ultra capacitors have a very high potential as well and recent advances in nano-technology will make the development of a new family of ultra-capacitors possible. In addition, hybridization of energy sources eliminates the compromise between the specific power and specific energy where multiple energy sources can be used in EVs, rather than one energy source. One energy source is selected for its high specific power while, the other for high specific energy.

\subsection{Impact on electrical power system}

Since electricity is the sole power source for EVs, it is important to evaluate the potential impact on the electrical power system. One of the concerns is that EV battery chargers generate harmonic contamination to the power system. This concern has been addressed by scientists and engineers who proposed many possible solutions. On the device level, new topologies of battery chargers are proposed while, on the system level, the adoption of new filters is a possibility for canceling the harmonics. Another possibility is compensating the harmonics generated by $\mathrm{EV}$ chargers [24]. Since the phase angles of harmonic currents generated by one charger are different from those generated by another, natural harmonic compensation or even cancellation may occur. Another concern of recharging the battery of EVs is the additional electricity demand especially that EV electricity consumption is relatively high - around 4000-6000 kWh/year for a car (as calculated previously). If vehicles are recharged during normal or peak periods, an additional burden on the power system is created. There are two possible solutions to this issue; the first is charging at night during off-peak hours when electricity consumption is normally low and the other is minimizing the peak current demand which can be achieved through the coordination between charging current and charging time to charge a group of EVs at the same charging station [25].

If users recharge their EVs at night during off-peak hours, they will benefit from cheap tariffs. Considering an off-peak cost of 3 cents per $\mathrm{kWh}$, the annual EV electricity cost is reduced from $\$ 400-\$ 600$ to $\$ 120-\$ 180$, hence 
efficient savings can be made. In this case, electricity should be generated continuously throughout the day to satisfy the above needs. For continuous electricity production, low-emissions high-efficiency power plants are more cost-effective, since their marginal operating cost is lower and their higher investment expenditure can be depreciated over more operating hours [12]. So, in addition to improving the well-to-wheel energy efficiency of EVs, they produce less $\mathrm{CO}_{2}$ emissions causing less air pollution.

\subsection{Charging infrastructure issues}

Although, large scale charging stations for EVs do not exist today, several charging options are possible.

The 2005 American Housing Survey showed that 76\% of the occupied housing units were single family structures and $63 \%$ of all occupied housing units had access to a garage [26]. For this market segment, it is convenient to charge the vehicle at-home during the night. On the other hand, at-home battery charging may not be practical for apartment inhabitants and those who cannot park near their home. In this case, public charging stations are necessary. At the beginning, it will be difficult to establish an extended network of electricity charging stations. It is possible however, to make use of the existing infrastructure of the gasoline charging stations; also, we can take advantage of the public parking areas. If normal charging is used, charging times of one to several hours are required [12]. In this case, a public charging station may become blocked for hours by only one customer. Additionally, the customer does not want to wait for hours until the vehicle is recharged. So, the availability of charging infrastructure in car parkings can solve this issue. In this case, the car could be charged during parking hours which are usually extended hours.

Otherwise, the "battery leasing" business model seems to be an appealing one especially in the initial stages of EV introduction. Depending on the customer's situation, the battery-leasing company may charge the battery or swap it with another fully charged one. This model has many advantages; it will resolve the range-anxiety issue by installing and maintaining a battery charging and switching infrastructure that will extend the driving range [9]. It will also eliminate the doubts about the durability of the battery and hence, more security to the EV customer. Moreover, it will significantly reduce the EV initial ownership cost, for example, the total price of our proposed urban EV will be reduced by $\$ 6,000$ which is the Li-ion battery cost.

Contrary to what most people think, EVs will require little initial expenditures on electrical infrastructure in the first stages of EV commercialization. The European Association for Battery EVs indicated that at least $23 \%$ of the cars in France can be electric cars without requiring significant increase in the electrical infrastructure, assuming off-peak hours charging. It is also likely that this number can be extrapolated to all Europe [12].

\subsection{Cost issues}

Currently, high cost is one of the major obstacles that hinder the commercialization of EVs. In spite of the common belief that all EVs are expensive, urban EVs may have reasonable prices.

The total cost of EVs consists of two parts: initial cost and operating cost. Although the initial cost of long-range EVs is higher than, or equal to, that of ICEVs, Table 4 shows that short-range urban EVs are considerably less expensive than ICEVs. While the average price of ICEVs is $\$ 23,000$, the projected cost of our proposed urban EV is $\$ 15,000$, out of which $\$ 6,000$ is the battery cost. There are basically two cost models for EVs; in the battery ownership model (BOM), the battery cost is included in the vehicle ownership price; whereas in the battery leasing model (BLM), the battery cost is separated from the vehicle ownership cost.

Since the battery cost is considered as the main component in the total EV cost, the ownership cost of EVs can be significantly reduced if battery costs are decreased. The BLM discussed above will relieve the cost burden of the EV customer whereby the battery ownership is separated from the vehicle ownership. On the other side, advances in battery technology and mass production will lead to reductions in battery costs in the future.

The operating cost is the other component of the EV cost which in turn includes maintenance cost, fuel cost, battery rental cost (in case of BLM) and infrastructure cost.

Maintenance cost for ICEV covers oil changes, brake replacement, and transmission maintenance; it costs around 4 cents per mile for a small sedan [27]. The maintenance cost of EVs accounts for only $25 \%$ of that of ICEVs $[9,18]$ so, the maintenance cost of EVs is estimated to be around 1 cent per mile.

The cost of electricity is on the order of 10 cents per $\mathrm{kWh}$ in the EV BOM and 6 cents per $\mathrm{kWh}$ in the EV BLM [9]. The electricity cost is assumed to be lower in the battery leasing model since the operators can buy electricity directly from the suppliers and thus, lowering the charging costs. For a $0.2 \mathrm{kWh} / \mathrm{mile} \mathrm{EV}$, the electricity cost is 2 cents per mile for the BOM versus 1.2 cents per mile for the BLM. The fuel cost of ICEVs calculated above is around 12 cents per mile.

The average battery rental cost is 8 cents per mile [9]. The battery rental cost can be further reduced if the batteryleasing company is a joint-venture between the battery manufacturer, dealer, electric power utility, and Oil 
Table 4 Comparison of electric and gasoline vehicle costs

\begin{tabular}{|c|c|c|c|c|}
\hline & & \multicolumn{2}{|c|}{ Urban electric vehicle } & \multirow{2}{*}{$\begin{array}{l}\text { Gasoline } \\
\text { vehicle }\end{array}$} \\
\hline & & $\begin{array}{l}\text { Battery ownership } \\
\text { model }\end{array}$ & $\begin{array}{l}\text { Battery leasing } \\
\text { model }\end{array}$ & \\
\hline Initial Cost $(\$)$ & & 15,000 & 9,000 & 23,000 \\
\hline \multirow{5}{*}{$\begin{array}{l}\text { Operating Costs } \\
\text { (\$/mile) }\end{array}$} & Maintenance Cost (cents/mile) & 1 & 1 & 4 \\
\hline & Fuel Cost (cents/mile) & 2 & 1.2 & 12 \\
\hline & Battery Rental Cost (cents/mile) & N/A & 8 & N/A \\
\hline & Infrastructure Cost (cents/mile) & 2 & 2 & N/A \\
\hline & Total (cents/mile) & 5 & 12.2 & 16 \\
\hline
\end{tabular}

Company. The final cost component in the EV deployment is the cost of deploying a charging infrastructure which is projected to be 2 cents per mile in the U.S. University of California model [9].

Table 4 summarizes the computed values for EV and ICEV costs.

The data in Table 4 shows that for both cost models, an urban EV is less expensive to purchase than a comparable gasoline vehicle. Similarly, the per-mile operating cost of an EV is significantly less than that of a gasoline one, especially in the BOM. It is expected that the per-mile costs of EVs will further decrease due to improvements in battery technology and electric motor efficiency.

\subsection{Range anxiety}

Some users have expressed their concern or fear of becoming stuck with a discharged battery in a limited-range vehicle, away from the electric infrastructure. With the urban short-range vehicle model proposed above, this concern is reduced since the EV will be used primarily for short city distances. That concern can be further reduced if the battery leasing model is applied whereby users will be allowed to exchange their discharged batteries with charged ones.

\section{Market penetration}

The previous analysis of the technical features of urban $\mathrm{EVs}$ is fundamental to understand their potential market penetration. Information like their speed limits, distance range and energy consumption is useful to specify which kind of consumers can be attracted to using them.

Defining the urban EVs potential market is a problem which has many degrees of freedom. Oil prices, national fuel resources, government incentive schemes, charging infrastructure, cost and others influence the choice of urban EVs over other vehicles. These factors will be analyzed in detail in the following paragraphs.

The urban EV is most favorable in regions where oil prices are high relative to electricity prices, such as Europe and the United States. The oil-exporting regions, such as the Middle East, currently subsidize local fuel consumption heavily whereas Europe and the US suffer from high oil prices. In Japan, the cost of electricity is high compared to the oil cost [2].

Adopting national incentive programs will stimulate the demand for urban EVs. Incentives schemes may have many forms such as government tax credits, emission regulations, policy legislation and fuel economy standards. US, Japan, France, Germany, United Kingdom and Singapore have adopted policies to support the development of the new energy vehicles industry for years. Financial policies usually include government rebates of $\$ 3000$ to $\$ 10000$ to each EV car owner (10\% of vehicle price). In Netherlands, the rebates reach $30 \%$ of the vehicle price $[2,28]$. These government refunds will make EVs less expensive to buy than comparable ICEVs. Implementing regulations that limit vehicle exhaust emissions is another form of governments' support to EVs. A European Union regulation requires reduction of average fleet emissions. Likewise, California's zero emissions vehicle regulation requires explicitly introduction of alternative fuel vehicles. On the other hand, fuel-economy standards are a major driving force behind using high energy efficiency EVs. Countries without regulations, like Middle East, India and Russia, suffer from very low fuel economy improvements. In contrast, there are significant fuel-efficiency improvements in the US, Europe, China and Japan [29]. Other incentives might include obliging public fleet operators to adopt a determined quota of urban EVs. The governments could also adopt appropriate city transport planning that takes into consideration the requirements of urban EVs regarding infrastructure and space.

Convenient charging is an essential requirement to urban EVs users. In a survey conducted in the United States, $81 \%$ of surveyed consumers would prefer to charge from home rather than in public charging stations. On the other hand, $79 \%$ would consider battery swapping as an alternative to charging their vehicle at home. Additionally, only $17 \%$ would be willing to spend $8 \mathrm{~h}$ in charging their vehicles. However, if the charging time is reduced from 8 to 4 , 
consumer willingness doubles [30]. Accordingly, the proposed urban EV with a battery capacity $20 \mathrm{kWh}$ is convenient to a significant market segment. The charging time is around $5 \mathrm{~h}$ using standard charging from conventional household sockets $(220 \mathrm{~V} / 16 \mathrm{~A})$ and $10 \mathrm{~min}$ by an industrial plug-in system [31]. Clearly, increasing public and private infrastructure will be necessary before the urban EV can be widely adopted. Although large-scale charging stations could be a key enabler to the EV, the cost would be significant. A station that can service 100 customers in a 24 -hour period at $50 \mathrm{kWh}$ per charge would cost $\$ 1.8$ to $\$ 3.0$ million. While the current charging infrastructure is very limited, it is predicted that the infrastructure will expand to reach 5.3 million charging stations by 2015 globally [30].

The cost of ownership is crucial in defining the target market of urban EVs. $69 \%$ of US consumers consider price the most important factor in a vehicle purchase and most of them expect to pay less than $\$ 30 \mathrm{~K}$ for an EV [30]; a finding that suggests that the proposed urban EV cost of $\$ 15,000$ will meet the expectations of a significant market segment.

The 60-mile proposed urban EV is mainly suitable for potential owners who drive short daily trips but, relatively long distances each year. Commuters who never or very infrequently travel more than 60 miles daily are good candidates for urban EVs; they constitute around $70 \%$ of US vehicles $[29,30]$.

According to a US market study, limited range and function - something universally cited by automakers as the most serious barrier to the EV's market success - is not such an obstacle after all. A key response in the consumer survey was that respondents felt comfortable with the performance limitations of contemporary EVs. Even though they were offered the potential of higher ranges at additional cost, almost half of those interested in EVs felt comfortable choosing EVs with a range of 60 or 80 miles per charge [32]. On the other hand, other consumers want the convenience and freedom associated with the equivalent of a full tank of gas. In another survey, $70 \%$ of the drivers would expect an electric vehicle to travel 300 miles before they would consider purchasing one [30]. This suggests that efforts will be needed to change the views of some consumers to be need-oriented rather than being driven by customs and habits.

Unsurprisingly, most of the prospective customers are largely unfamiliar with EVs, especially the urban EV category. That was the case with hybrid vehicles decades ago. The current familiarity with hybrid vehicles comes from huge education efforts by some vehicle manufacturers for over 10 years at a cost of more than $\$ 1$ billion [30]. In the initial urban EV deployment phases, there will be many social, psychological, perceptual and emotional barriers to overcome; worry and skepticism result from switching to a new technology after being used to conventional vehicles, also feelings of lost freedom arise due to the limited range and the possible recharging issues for EVs. Additionally, there is a uniform community perception that expects all vehicles to satisfy all purposes and all roads to serve all vehicles. The ultimate result of all this is a resistance that discourages change and innovation. In view of this, effective marketing campaigns should focus on educating and correcting wrong preconceptions about urban EVs.

On the other hand, it is unlikely that some groups adopt the urban EVs. This category includes large construction and agricultural trucks, high-income families with two or more children, vehicles with 5 or more occupants, commuters with long daily driving distances and rural baby boomers who are not traditional adopters of new technology.

Based on the above market analysis, it is possible to define the niche markets that are feasible for urban EVs. One important niche market is neighborhoods and areas where speeds are controlled. Highly congested cities and urban centers with high traffic are perfect candidates for the use of urban EVs. A subset of this category is those individuals who drive short distances to public transport (bus, metro or train) stations everyday. A second niche market is resorts which are usually located at seashores, mountains, lakes, parks or in other environmentally sensitive areas where green environments are highly appreciated. Using ICEVs in those areas would lead to damages to the natural environment. A third market is urban public transport vehicles and taxis that run around the city. Another target market is government vehicles such as urban post delivery vehicles.

Unfortunately, a quantitative analysis of urban EV market penetration cannot be made at this time. Getting global and credible market data is difficult. For a realistic market analysis, data for both stated preferences and observed selections would be ideal. But, currently research and sales data is fragmentary and disaggregated. It is however, projected that global market penetration of urban EVs is approximately $2 \%[29,32]$. This is probably a small market segment due to the reasons discussed above (lack of awareness, charging issues,...) nevertheless, it is a potentially growing one.

Although detailed market studies are needed, our preliminary analysis reveals that the United States and Europe are immediate potential markets for urban EVs more than markets like Middle East, China and Japan. It is forecasted that EVs will penetrate most heavily in Europe at nearly $18 \%$ by 2020 . In contrast, no penetration of EVs is expected in the Middle East by 2020 [29].

It is thus concluded that a ready market exists for urban EVs priced competitively and adapted to meet customers' expectations. Those vehicles also need to be marketed appropriately to emphasize their positive advantages such 
as their high fuel efficiency. At the same time, certain barriers need to be overcome before large-scale market deployment becomes possible.

\section{Commercialization}

There is no doubt that promotion is an important factor in EV commercialization. Proper engineering, commercial and marketing strategies are essential in the development of urban EVs. The overall strategy should take into account how to exploit urban EVs competitive edge, meet market demand and win stakeholders support. The cooperation, as well as, the commitment of governments and public authorities, manufacturers, electric utilities and users is key to EV success. Technical support from academic institutions and industrial organizations can strongly influence the adoption of EVs. Customer awareness is also crucial for the development of EVs market [5] where people being aware of EV technology become potential customers. Moreover, they talk to other people not knowing the new technology. This way, knowledge about EVs will spread over the whole market via word-of-mouth and turn more people into potential customers. The more EVs are sold the more experience manufacturers get with the technology which in turn leads to decreasing production cost. Eventually, this will lead to price reductions.

\section{Conclusions}

Energy conservation and environmental protection are the main driving forces behind the development of electric vehicles. The business case developed above encourages a fast deployment of short-range (less than $100 \mathrm{~km}$ ) lowspeed (maximum $90 \mathrm{~km} / \mathrm{h}$ ) urban EVs. This is because of the various benefits they offer such as high energy efficiency, reductions in petroleum use and greenhouse emissions, and national energy security. The proposed urban EV, with $27 \%$ well-to-wheel efficiency, is twice as efficient as an ICEV and the annual fuel cost of the urban EV is 6 times less than a gasoline one. Moreover, the Wellto-Wheel $\mathrm{CO}_{2}$ emissions of the $\mathrm{EV}$ are about 2.5 times less than those of a gasoline vehicle. Besides, urban EVs provide additional benefits such less noise, reduced maintenance, convenience of home recharging and finally a green image.

Since the 19th century there has been several attempts for EV use however, none of them achieved the required success. Many people believe that a choice has to be made between EVs and other vehicles (conventional vehicles or alternative vehicles). However, this is definitely not the case since each technology serves a different market and addresses a distinct demand. Thus, it is a question of both/ and rather than a question of either/or. In spite of having some limitations, urban EVs seem to be a good choice for cities since their potential drawbacks are few and can be mitigated. The author believes that it is now time to move on so, in this paper some techniques are introduced to mitigate the current limitations of EVs. Using a relatively small Li-ion battery and hybridization of energy sources address the weight, performance and range issues of $\mathrm{EV}$ energy sources. Charging in off-peak hours is one proposed solution to reduce the additional demand on the electrical power system caused by the charging of EVs.

A rapid wide deployment of EVs is unlikely due to several issues in commercialization. However, the main idea is to first activate the EV chain reaction. Then, technological advancements will act as a catalyst to speed up this reaction. The chain reaction would start by the introduction of urban EVs then, support and interest in investment would enable mass production. The low initial price, caused by mass production, will lead to a high customer satisfaction and hence, high demand for EVs. High demand will in turn lead to high sales and thus, EV success. Battery technological advancements will be the main catalyst in the above reaction.

Open Access This article is distributed under the terms of the Creative Commons Attribution License which permits any use, distribution and reproduction in any medium, provided the original author(s) and source are credited.

\section{References}

1. International Energy Outlook (2007) Report \#DOE/EIA-0383 (2007), Energy Information Administration, US Department of Energy, May 2007

2. Zhang F, Cooke P (2009) "The green vehicle trend: electric, plugin hybrid or hydrogen fuel cell?", Dynamics of Institutions and Markets in Europe

3. Eberle U, Helmolt R (2010) Sustainable transportation based on EV concepts: a brief overview. Energ Environ Sci J 3:689-699

4. Dixon J (2010) "Energy storage for electric vehicles", IEEE International Conference on Industrial Technology, March 2010

5. Wansart J, Schnieder E (2010) Modeling market development of electric vehicles, 4th Annual IEEE Systems Conference, April 2010

6. Simpson A (2006) "Cost-Benefit Analysis of plug-in hybrid electric vehicle technology", 22nd International Battery, Hybrid and Fuel Cell Electric Vehicle Symposium and Exhibition, October 2006

7. Gassman S (2009) "The Electric Car: A Brief History and What's Next?", BSC Sustainability Services

8. IEEE-USA Board of Directors, "Position Statement Plug-in Electric Hybrid Vehicles", 2007

9. Becker T, Sidhu I, Tenderich B (2009) "Electric Vehicles in the United States: A new model with forecasts to 2030", Center for 
Entrepreneurship and Technology, University of California, Berkeley, no. 2009.1.v.2.0, August 2009

10. Huo H, Zhang Q, Wang M, Streets D, He K (2010) Environmental implication of electric vehicles in China. Environ Sci Tech J 44:4856-4861

11. Environmental Protection Agency (EPA), Fuel Economy Guides, Online: http://www.fueleconomy.gov/feg/download.shtml. Accessed 2 August 2010

12. European Association for Battery Electric Vehicles, "Energy consumption, $\mathrm{CO}_{2}$ emissions and other considerations related to battery electric vehicles", Online: http://ec.europa.eu/transport/ strategies/consultations/doc/2009_03_27_future_of transport/ 20090408 eabev_\%28scientific_study\%29.pdf, April 2009. Accessed 1 August 2010

13. U.S. Department of Energy (DOE), Light-Duty Vehicle Publications, Online: http://www1.eere.energy.gov/vehiclesandfuels/avta/ publications/ld_library.html. Accessed 12 September 2010

14. U.S. Energy Information Administration, Electric Power Monthly: August 2010 Edition. Online: http://www.eia.doe.gov/cneaf/ electricity/epm/epm_sum.html. Accessed 11 September 2010

15. U.S. Department of Energy (DOE). "Federal Register Vol. 64 No. 113" U.S. GPO, 11 June 2000

16. Notter DA et al (2010) Contribution of Li-ion batteries to the environmental impact of electric vehicles. Environ Sci Tech J 44 (17):6550-6556

17. Hori Y (2004) "Future vehicle driven by electricity and controlResearch on four-wheel-motored", IEEE Transactions on Industrial Electronics, vol. 51, no. 5, October 2004

18. Chan CC (2002) The state of the art of electric and hybrid vehicles. Proc IEEE 20(2):247-275

19. Chau KT, Wong YS, Chan CC (1999) An overview of energy sources for electric vehicles. Int $\mathrm{J}$ Energ Convers Manag 40 (10):1021-1039

20. Wong YS, Chau KT, Chan CC (2000) "Optimization of energy hybridization in electric vehicles", Proceedings of 17th International Electric Vehicle Symposium, October 2000
21. Chan CC, Lo EWC, Shen WX (1999) “An overview of battery technology in electric vehicles", Proceedings of 16th International Electric Vehicle Symposium, October 1999

22. Gaines L, Cuenca R (2000) "Costs of Lithium-Ion Batteries for Vehicles", United States Department of Energy, Center for Transportation Research, Energy Systems Division, May 2000

23. Cheah L, Heywood J (2010) "The Cost of Vehicle Electrification: A Literature Review", MIT Energy Initiative Symposium, April 8, 2010, Cambridge, Massachusetts

24. Chan MSW, Chau KT, Chan CC (1998) "Modeling of electric vehicle chargers", Proceedings of IEEE International Conference of Industrial Electronics, pp. 433-438, August 1998

25. Chau KT, Chan MSW, Chan CC (2000) "Current demand minimization by centralized charging coordination", Proceedings of 17th International Electric Vehicle Symposium, October 2000

26. Vyas A et al. (2007) "Plug-In Hybrid Electric Vehicles: How Does One Determine Their Potential for Reducing U.S. Oil Dependence?", Electric Vehicle Symposium No. 23, December 2007

27. American Automobile Association (AAA), "Your Driving Costs 2008", Online: www.aaaexchange.com/Assets/Files/ 20084141552360.DrivingCosts2008.pdf. Accessed 21 September 2010

28. Xiang Z et al (2008) "Prospects of New Energy Vehicles for China Market", Proceedings of Hybrid and Eco-Friendly Vehicle Conference, pp. 1-11, December 2008

29. McKinsey Global Institute, "Averting the next energy crisis: The demand challenge", March 2009

30. Deloitte Development LLC (2010) "A Customer View of Electric Vehicle Mass Adoption in the U.S. Automotive Market"

31. Perujo, Ciuffo B (2009) "Potential Impact of Electric Vehicles on the Electric Supply System", European Commission Joint Research Centre, Institute for Environment and Sustainability

32. Green Car Institute, "The Current and Future Market for Electric Vehicles", Online: http://www.greencars.org/pdf/gcimarketing.pdf. Accessed 1 February 2011. 